\title{
The Influence of New Media on Customers Buying Behaviour in the Wine Sector: Empirical Models and Simulation of Information Diffusion Among Potential Customers
}

\author{
Marco Remondino \\ Department of Economics \\ University of Genova, Italy \\ Email: marco.remondino@economia.unige.it
}

\begin{abstract}
We empirically evaluate the impact of media and information on wine buying decisions. In particular, the analysed factors are: advertisements/reviews on traditional media (e.g. magazines, newspapers, TV); advertisements/reviews on new media (e.g. forums, blogs, websites); price; brand; word of mouth; previous personal experience. A growing number of specialized sites, blogs and forums is devoted to wines and many of those feature competent, professional reviews and suggestions. Since wine is a traditional good, not linked to technology, the research question is to empirically analyse whether these new channels have an influence on consumers' behaviour and decisions, or not. In order to study this, a questionnaire has been created and spread to potential Italian buyers, gathered from specialized websites and blogs, wineries or social channels. A Likert scale (1-7) has been used to evaluate the level of agreement towards the impact on buying decision of the mentioned factors. A total of 460 full questionnaires have been returned; the data have been analysed by statistical means, to compare the impact on consumers' behaviour of new media compared to more traditional sources of information. After that, a simulation model has been used, parametrized with the data coming from the questionnaire, to show how new and social media, when used as a marketing and communication mean from the company, can impact the diffusion of a message towards potential customers, in this specific use case.
\end{abstract}

Keywords - influence of new media, customers buying behaviour, wine sector, empirical models, simulation, information diffusion, potential customers

\section{INTRODUCTION}

New information channels like, among others, social media, blogs, forums, chats and websites have vastly changed the way in which "word of mouth" (WOM) about products is spread among potential customers, introducing new approaches for the acquisition and retention of purchasers, as discussed in, e.g. Osenton 2002 and Wind et al., 2002. This is particularly true for digital and technological goods, but also traditional ones are affected.

Besides direct communications from companies, Seneca and Nantel (2004) talk about "online interpersonal influence", hinting at the principle that each consumer can have influence on others' decisions, through social networks and other interactive media.

The WOM which takes place on virtual places, instead of the real world, is usually referred to as e-WOM. This has proven to be a very important factor, affecting buying decisions of technological goods (e.g. Cellular phones, as shown in Karjaluoto et al., 2005). Since specialized new media (e.g. Blogs, sites and forums) exist also for more traditional goods, it is of growing concern to look at consumer buying decision process and cast light on the factors that determine their final choice.

The purpose of this research is to empirically evaluate the impact of different new and traditional communication media on wine buying decisions and compare these factors with others, like brand, price and previous personal experience. Wine has been selected as the target good for the present research, since it's a very traditional good, but also a social one. Besides it can be considered emotional, since it touches human senses (taste, but also smell and, to a lesser extent, sight. There are wine collectors and wine experts, but also many "non-professional" wine enthusiasts all over the world.

Other researches have pointed out a number of factors that can influence the wine selection process (Jenster and Jenster 1993; Koewn and Casey 1995; Batt and Dean 2000; Hall et al 2002). Howard and Stonier (2002), stress that "there is more to wine than simple tangible qualities".

So, while taste, quality, origin, brand are definitely important factors, not many people are actually so acknowledged to really sort out these features and hence other factors, like price, communication, involvement, situation and even packaging seem to be leading the consumers' buying process for this particular good.

In order to define the importance of different factors in wine buying decision, a questionnaire has been proposed to potential wine buyers; the channels used to spread the questionnaire have been Italian specialized websites and blogs, wineries and social channels (Facebook and direct email). A total of 460 questionnaires have been collected and analysed. 
A Likert scale (De Winter et al, 2010) ranging from 1 to 7 was used for each question, where 1 is "not agree" and 7 is "fully agree".

For the second part of the research, a simulation model has been used, to test and evaluate the impact of social media in the diffusion of information about a traditional good, like wine is.

\section{WINE AS AN "EXPERIENCE GOOD”}

Wine is a complex commodity that over the years has undergone a significant change in its methods of production and consumption. In recent decades, in fact, in traditional producing countries, the consumption of this drink has gone from nutritional reasons to the pure pleasure of pleasure drinking. Wine is consumed on special occasions and to socialize both inside and outside the house and has become a highly differentiated and valuable product.

In particular, it was during the new millennium that the passage of this product from nutritious to cult is sanctioned: new initiatives are born aimed at attracting consumers such as "open cellars" aimed at a tasting of the product in the context of production to understand in depth the origins and attributes. The management of the wine shelf in the large retail outlets has also changed, a change that is not intended to trivialise the experience of buying this product. Exports therefore represent $40 \%$ of production, in relation to a volume produced of 47.5 million hectolitres.

In addition to this cultural change, wine has an important peculiarity for which it has been chosen for this research: it is defined as an "experience good", which means that unlike other goods, it can be evaluated in qualitative terms by the consumer only after tasting and consumption (following the classification devised by Nelson, 1970).

The fact that it is impossible to assess the quality of the product before the purchase stage means that the wine market is characterised by a strong information asymmetry between the producer and the consumer. The first has as its objective linked to the production and to the sensory characteristics of the beverage, while the consumer can limit himself to conjectures and deductions on the quality of the output on the basis of attributes that will be further examined or on the basis of friends' advises or, also, on the basis of reviews found on specialised journals or websites. The path described above has also encouraged the policies of differentiation of producers aimed at obtaining a longterm competitive advantage, contributing to a greater attention to variety.

In addition, consumers who want to buy wine have to face a high complexity linked to a wide range of offerings made up of countless variants and brands. For these reasons, wine has also been defined as a "cognitive product" (Mattiacci et. al). This means having "an intrinsically complex structure, which requires a non-trivial cognitive endowment, both in purchase and in consumption, to the final demand".

The experience and knowledge that the consumer has acquired over time play a fundamental role in the possibility for the buyer to correctly and realistically assess the price of a bottle of wine, allowing the purchase of a product that actually has a perceived quality as aligned as possible to the expected quality; the same authors also stress the importance of two other variables that affect awareness of the wine product system: age and place of birth.

The complexity and the wide offer contribute to a high perceived risk for the consumer or to a high uncertainty regarding the negative consequences of the choice made; this leads buyers to implement the so-called risk-reduction strategies (RRS), i.e. mechanisms aimed at reducing uncertainty even if the information available is not adequate and the consequences of the purchase are unpredictable.

The perception of risk is influenced by external factors and also by specific variables of the individual, the propensity to risk is in fact a subjective variable, as is experience; according to the literature, for example, uncertainty is reduced to the rise of experience acquired in a specific field (Lacey et al., 2009). Nevertheless, it is possible to identify various generic risk reduction strategies such as: information retrieval, brand loyalty, seller's high reputation, price, retrieval of guarantees and reassurances (figure 1).

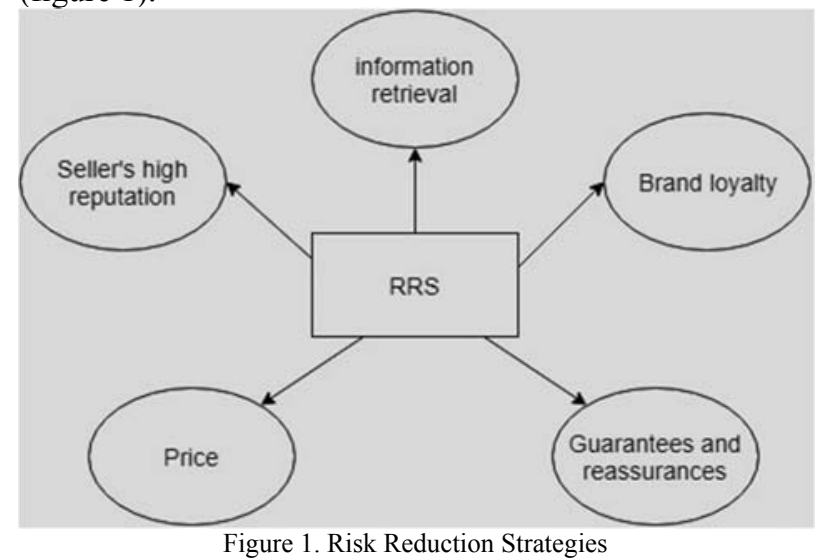

These notions have been applied to the wine market, starting from the assumption that the decision to buy wine is dominated by fear and anxiety because most consumers do not have the knowledge to make informed decisions, but do not want to appear totally incompetent (Gluckman, 1986).

The authors Lacey, Bruwer and Li (2009) state that, in choosing wine, the consumer perceives four types of risk: the functional risk in relation to the potential bad taste of the bottle chosen, the social risk of a lack of approval of the wine by family and friends, the financial risk due to a very bad ratio between the total sum of costs incurred and the 
perceived quality and finally the physical risk related to the state of drunkenness.

In the same way, a series of Risk Reduction Strategies specific to this market can be identified, the authors outline two in particular: the opportunity to taste wine before buying through free samples or through a tasting at the point of sale and personal recommendations.

According to Spawton (1991), however, all the mechanisms mentioned above are adaptable to the choice of wine, the consumer tends to buy products of brands of which he has already had experience (personal previous experience), tends to acquire information from others and from sales staff, is often based on price and format of packaging and label.

As a further introduction to the motivations for this research, it is useful to distinguish "intrinsic attributes" from "extrinsic attributes".

Intrinsic attributes are physical characteristics of the product that cannot be modified without totally altering the nature of the product itself, and are therefore specific to each output; in the case of wine they taste and consequent aromas (bouquet), but also colour, fall into this category (figure 2). The consumer/buyer of wine has difficulty in finding information about these attributes in the phase prior to purchase, except for repeated purchases or products that have already been consumed previously. Nevertheless, according to a study conducted in Italy (Hertzberg and Malorgio), taste is the attribute that most affects the choice of the consumer along with the opinions of friends. About $65 \%$ of respondents to the survey indicate: opinions of friends and preliminary tasting as the most effective methods to promote and encourage the purchase of a bottle of wine.

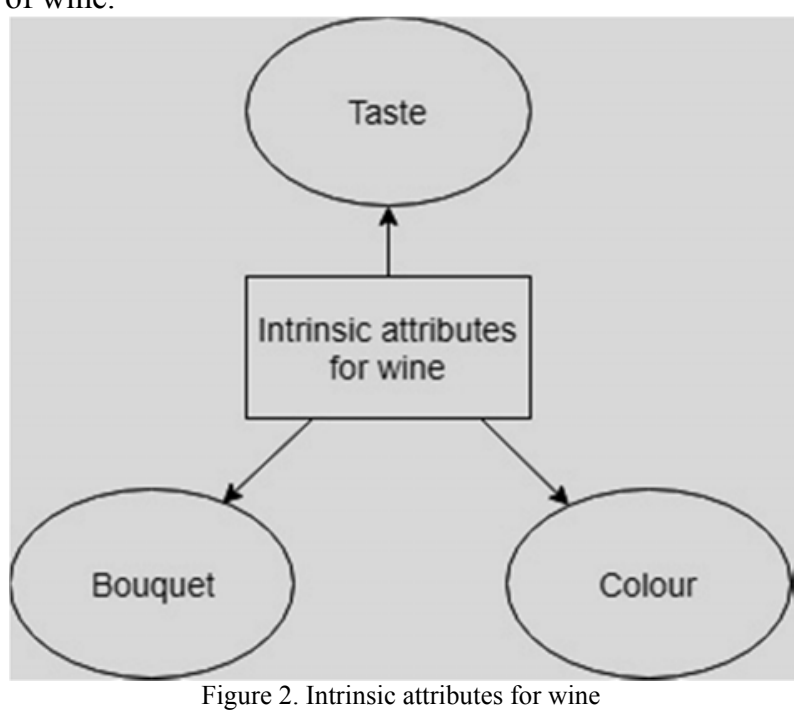

Extrinsic attributes (figure 3) also refer to a specific product, but unlike the previous ones they do not belong to it in the strict sense; this category includes external factors such as: manufacturer's brand, origin certification, price and label.

The blog "The numbers of wine" provides a ranking of these attributes in relation to the importance of choosing wine for consumption outside the home.

The top of the list is the manufacturer's brand, particularly in situations of risk or information asymmetry (such as the one described above and depicted in figure 1). Immediately after brand, it is the origin of the wine that plays a fundamental role in consumer choice. The latter, in relation to complex decisions like this, tends to adopt a heterogeneous attitude towards different outputs basing its perception of attributes and the resulting preferences on the basis of the country or region in which they were produced, this phenomenon is called the "country effect".

Another extrinsic attribute, price, seems to take on a minor role. The monetary value of a wine bottle is also considered as a cognitive shortcut and falls within the RRS mentioned above (figure 1); it is used as a signal of quality by less experienced consumers, which tend to protect themselves from poor quality by acquiring more expensive bottles.

Finally, the last extrinsic attribute mentioned is the label, the latter represents both an important tool to reduce the information asymmetry between consumer and producer and an important factor of differentiation of the bottle from the aesthetic point of view.

From a design point of view, it has been shown that colour, images and logos on the label have a greater impact on women than on men (Thomas \& Pickering, 2003).

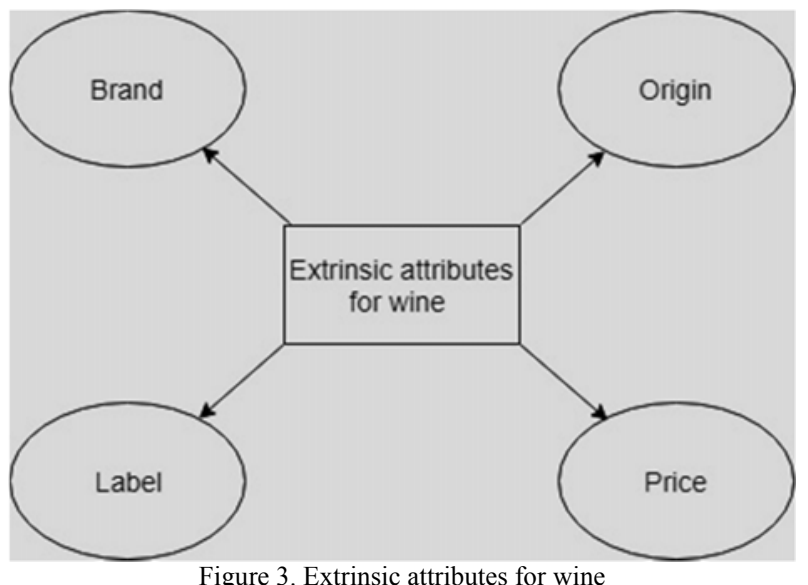

III. WINE 2.0

While dividing the different products and services on the market today into unique categories can be complex, there are clearly outputs that, in relation to a higher level of consumer involvement, require a broader and more indepth set of information to encourage the buyer to make a decision and conclude the purchase. The authors Vrana and 
Zafiropoulos (2012) include in this category those products whose quality is difficult to assess before consumption. Further confirming the literature previously examined, they mention both tourist services, therefore an intangible output, and wine.

As mentioned in the previous paragraph, wine is a complex product, presented as an experiential and cognitive good, linked to a high complexity in the consumer's choice of purchase and a high perceived risk.

The authors Szolnoki, Taits and Nagel (2014) also claim that it is in fact an output full of emotions and that anyone who consumes wine is inclined to have their own opinion and wishes to share it with others.

Wine therefore seems destined to benefit from the use of social media, authors, Agnoli et al. (2013) state that the adoption of social media as a marketing and communication tool in the Business to Consumer context is more suitable for those sectors whose products require a high level of trust and for which the purchasing process is mainly based on information search.

Wine, a food product, is part of the Pavitt taxonomy of the traditional sector including those outputs related to people and homes (textiles, clothing, food, furniture and furnishings) in which Italy excels worldwide through a competition on factors such as: quality, brand, image and tradition.

The values connected to the tradition and art of wine production are often considered discordant and not suitable for their communication through the typical tools from web 2.0 , such as blogs and social media.

The combination of new technologies and traditional sectors of the economy is however becoming increasingly solid.

A. Gori, sommelier and journalist, states that the use of social media and Web 2.0 in the wine sector is functional because the consumer, in a situation of information asymmetry with respect to the producer, needs the information available on blogs, social networking sites and content communities to make their choice of consumption, other authors argue that consumers can use social media as alternatives to the classic search engines to find any type of information about wine (Szolnoki et al, 2014). Gori himself also states that the set of information available ex ante using these tools has a considerable influence on the performance of the wineries and that is why their use must also comply with the guidelines identified by Kaplan and Haenlein (2010).

From a chronological point of view, the evolution that has guaranteed the growth and diffusion of social media has as its basic pillar the transition from Web 1.0 to Web 2.0 , in the same way the communication strategies of wine companies were able to exploit different channels in relation to interactivity with the consumer. For this reason, it is possible to distinguish the concept of Wine 1.0 from that of Wine 2.0
In the first case, the wineries set up their presence on the Web through sites that were the simple transposition of the paper brochure; the set of information available to the user included: product catalogue and their characteristics, contact details for the company and sometimes a simple software to give the customer the opportunity to buy bottles online. The website was not interactive and users were therefore not allowed to post comments and reviews.

Wine 2.0, on the other end, is intended to engage consumers through social media in a way that takes advantage of user-generated content (UGC). In figure 4 a graph is shown for social media usage connected to wine.

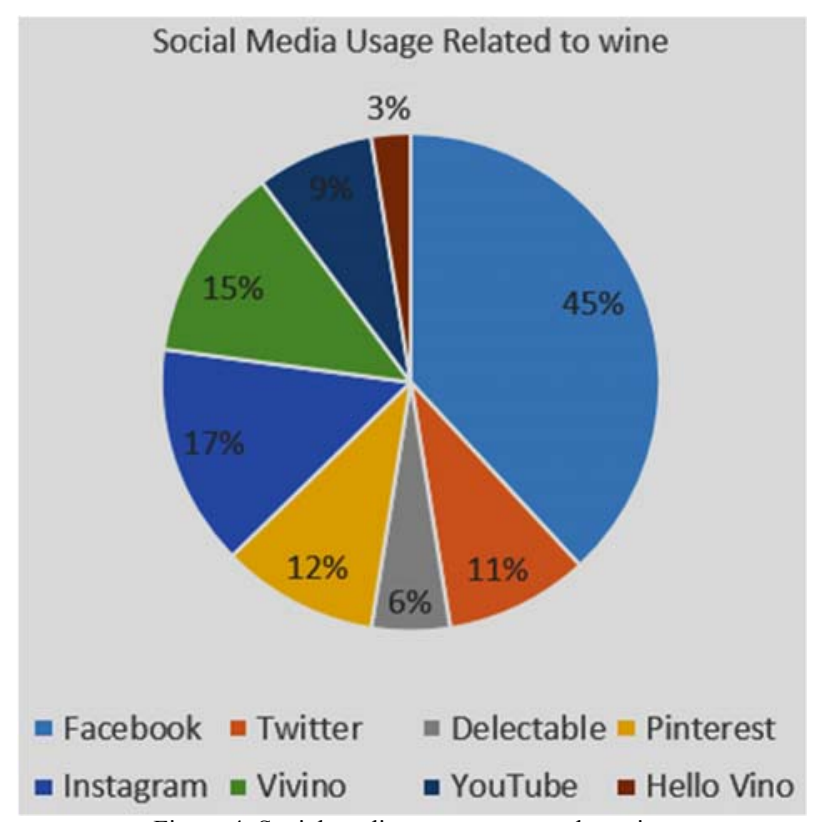

As is often the case in the technology sector, Wine 2.0 is hence intended as a successor to version 1.0, of which it incorporates the main components, while guaranteeing a higher level of interactivity.

The authors of the book "Wine Marketing \& Sales" state that the advent of Wine 2.0 has provided consumers with more tools to learn about a brand while at the same time allowing companies to build new types of relationships with their customers. Determining one's approach to using Web 2.0 tools is critical and the authors identify three possible options: ignore the Wine 2.0 phase, monitor and respond, or participate proactively.

In the first case, the winery management, supporting for example the idea that Wine 2.0 is only a transitory phase and of short duration, decides not to invest company resources in these channels; this first option is rarely chosen in today's marketing context in relation to the now obvious change of the consumer in his consumer journey and the continuous growth of the number of users of the Web. 
The intermediate alternative is to monitor and track, through analysis tools offered by Google and social networking sites, what is said about your business on the Web. This strategy requires less time than the third alternative, but at least allows the winery to be aware of what is happening on digital platforms. Finally, the proactive approach is translated into an additional effort compared to the traditional marketing strategy of the wine business, and not a substitute. Integration with other communication mix tools, coherence and activism must be the pillars of a credible, valuable and therefore effective communication strategy.

In this case, the winery participates directly and involves its customers by providing valuable content through different types of social media. The authors also state that the winery should not confine itself to conveying its own content, but that it should also involve and participate in the activities of other parties (customers, suppliers, Influencers and others) active on the Web.

A research conducted by the communication agency BeSharable on 3439 Italian wine companies, shows that $94 \%$ of the analysed ones have a website, that includes an English version in $96 \%$ of cases and an Italian version in $4 \%$. As far as the use of social networking sites is concerned, $73 \%$ have a Facebook profile; the same wineries are also present on other platforms, but with much lower percentages (32\% are present on Twitter, $16 \%$ on Instagram and $14 \%$ on Google + ).

Mills and Pitt (2011) state that in the wine industry, the website is functional to convey information on different aspects: prices, information on products, location of the cellar, contacts and educate the user. For this reason, the legibility of the winery's site or its intelligibility becomes a fundamental variable to outline the effectiveness of the company's communication strategy. In addition to this, the authors themselves state that the level of navigability of the site has a direct impact on the level of consumer confidence and involvement, both fundamental elements of an effective digital communication strategy; for this reason, it is necessary to follow and respect simple guidelines.

In relation to social networking sites, the 6 companies considered by Capitello et al. (2013) showed a heterogeneous situation: some of them had only one profile on Facebook while some managed profiles on at least two other platforms, such as YouTube. Again, the researchers stated that those who, driven by the spread and success of these new tools, had activated several channels at the same time, were obliged to focus their attention and efforts on only one or a few. The data show that the highest levels of visibility on the Web were not achieved by companies with a wider mix of social media used, but rather by those who were more creative in terms of the significance and value of the content conveyed.

Another Web 2.0 fundamental tool, widely used in the wine sector, is constituted by blogs. The "wine blog" is defined by Thach (2010) as a Wine 2.0 tool, in addition to social networking sites and content communities, aimed at engaging wine consumers. Wine blogs are interactive sites set up by a blogger or group of bloggers who write speeches about this product. Anyone can set up one and for this reason there are blogs of wine lovers, blogs of wineries and blogs of anyone interested in publishing their opinions on a bottle of wine consumed.

Thach herself says that wine blogs are not monitored and there are no official guidelines or rules regarding the type of topics that can be covered, so the same wine can be the subject of countless types of content depending on the author and for the same reason, some content can compete for sales in a winery and others can become an obstacle.

The researcher has therefore conducted a research to understand which types of contents can be conveyed by this tool and has divided the different wine blogs into categories. The results show the existence of 9 categories of wine blogs on the Internet: wine reviews, wine and food, wine education, specific region, wine \& culture, winery blog, wine business, winemaking and viticulture, others.

\section{THE QUESTIONNAIRE}

As stated in the introduction, in order to define the importance of different factors in wine buying decision and investigating the effect of the new media channels on customers' buying decisions, a straightforward questionnaire has been proposed to potential wine buyers. The channels used to spread the questionnaire have been Italian specialized websites and blogs, wineries and social channels (Facebook and direct e-mail). A total of 460 questionnaires have been collected and analysed.

The purpose was to keep the questionnaire as plain and simple as possible, so to encourage people to complete it. The questions about the factors of influence on buying decision used a Likert scale ranging from 1 to 7 , where 1 is "not agree" and 7 is "fully agree". The respondents were not linked to a total of "points" to scatter on the various questions. Rather, they could give any vote to any factor.

In Joost et al (2010) we read that Likert scales are widely used in various domains such as behavioral sciences, healthcare, marketing, and usability research. When responding to a Likert scale, participants specify their level of agreement to statements with typically five or seven ordered response levels. Likert item data have distinct characteristics: discrete instead of continuous values, tied numbers, and restricted range.

The questions asked were:

where did you find this questionnaire? [blog/website, winery, personal email, facebook,]

- age

- sex

- geographical region

- average monthly expense in wines

- impact of brand on purchase decision [1..7, where 1 don't agree and 7 fully agree] 
- impact of price on purchase decision [1..7, as above]

- impact of advertisements or reviews on traditional media (magazines, newspapers, TVs, ...) on purchase decision [1..7, as above]

- impact of advertisements or reviews on new media (websites, forums, blogs, social networks...) on purchase decision [1..7, as above]

- impact of word of mouth (advice from friends, relatives, ...) on purchase decision [1..7, as above]

- impact of past personal experience on purchase decision [1..7, as above]

Since even the same wine (same kind and brand) changes on a per year basis, the last question refers to a personal experience on the product of the previous years, and this was clearly stated in the instructions. This is important to check if customers prefer their experience, even if the product may significantly differ from the one they tasted in the past, or rather more up-to-date reviews and advice coming from other sources.

The questionnaire was spread through specialized sites and blogs (whose titles are in the acknowledgments), direct emails, Facebook (or other social networks) pages and physical and web wineries. The majority of the results were gathered from the questionnaires spread through sites and blogs ( 267 out of 460 , i.e. about $58 \%$ ). Only 27 were those coming from direct email (slightly less than 6\%), while $20.7 \%$ came from the social networks (95 questionnaires) and $15.4 \%$ from wineries (71). Since the email is a social media and the number of those questionnaire is negligible, it has been decided, for the analysis, to put together those questionnaires and the ones coming from the social networks and consider them as a whole, coming from "social channels".

The global average age of the respondents was 41.6, with a median of 41 and a mode of 35 . For the respondents coming from blogs or websites, those data change to 42.3, 42 and 50 respectively, while for those coming from wineries they account to $42.9,43$ and 50 respectively. The respondents that received the questionnaire via email had an average age of 34.1, with a median of 33 and a mode of 22. Last, those who got the questionnaire through Facebook had an average age of 40.9 , with a median of 41 and a mode of 43 . The majority of the respondents were males, 341 , versus 119 females (74\% and 26\% respectively).

As to geographical regions, the questionnaire was spread through Italian sites, blogs and wineries, so almost the totality of respondents were actually living in Italy, except four of them (out of 460, so a negligible percentage). Most people (130 out of 460 , i.e. about $28 \%$ ) were from Piemonte, follow by Lombardia (16\%), Veneto $(12 \%)$ and Toscana (10\%). After those, Lazio and Emilia Romagna (7\% and 6\% respectively), Trentino and Friuli (both at about 4\%), Marche, Umbria, Sardegna, Puglia, Sicilia,
Liguria and Calabria (among 1\% and 2\%) and other regions, namely Basilicata, Abruzzo and Valle D'Aosta at under $1 \%$.

An important parameter is the average monthly expense. The average was $88.90 €$, which is quite high, showing that most of the respondents use to heavily invest in wines. In the following table, a division per classes of expense.

TABLE 1. DIVISION IN CLASSES OF EXPENSE
\begin{tabular}{|l|r|}
\hline Class & Total \\
\hline $0-49 €$ & $33,86 \%$ \\
\hline $50-99 €$ & $32,96 \%$ \\
\hline $100-149 €$ & $13,90 \%$ \\
\hline $150-199 €$ & $6,73 \%$ \\
\hline $200-249 €$ & $5,16 \%$ \\
\hline$>250 €$ & $7,40 \%$ \\
\hline
\end{tabular}

The following table shows the same classification, operated for each of the media through which the data were gathered (each column totals $100 \%$ ).

TABLE 2. CLASSES OF EXPENSE VS PROVENIENCE OF QUESTIONNAIRE

\begin{tabular}{|c|c|c|c|}
\hline Class & Sites/Blogs & Wineries & Social Nws \\
\hline $0-49 €$ & $30,0 \%$ & $25,4 \%$ & $46,7 \%$ \\
\hline $50-99 €$ & $32,0 \%$ & $43,7 \%$ & $28,7 \%$ \\
\hline $100-149 €$ & $16,6 \%$ & $15,5 \%$ & $7,4 \%$ \\
\hline $150-199 €$ & $6,7 \%$ & $4,2 \%$ & $8,2 \%$ \\
\hline $200-249 €$ & $7,1 \%$ & $0,0 \%$ & $4,1 \%$ \\
\hline \multirow[t]{2}{*}{$>250 €$} & $7,5 \%$ & $11,3 \%$ & $4,9 \%$ \\
\hline & $100,00 \%$ & $100,00 \%$ & $100,00 \%$ \\
\hline
\end{tabular}

It is evident how the people coming from the social media have the highest concentration in the lower classes of expense (about $75 \%$ under $100 €$ and about $47 \%$ under $50 €)$. People coming from wineries have the highest percentage (among the three media) of very high expense $(11.3 \%$ over $250 €)$, while those coming from specialized websites and blogs are more evenly divided, with the majority (almost 80\%) with expenses lower than $150 €$ and about $20 \%$ higher.

\section{ANALYSIS OF DATA}

The most relevant part, for the present study, is constituted by the replies to the Likert based questions. Several analyses have been carried on, starting from the basic statistical ones.

\section{A. Counting Votes}

First, the data have been collected and counted, meaning, how many replies have been given for each media, with each possible vote [1..7]. This is reported in the following tables and charts. 
TABLE 3. COUNT OF DATA PER VOTE

\begin{tabular}{|c|c|c|c|c|c|c|c|c|}
\hline & 1 & 2 & 3 & 4 & 5 & 6 & 7 & \\
\hline Brand & 37 & 40 & 74 & 106 & 100 & 65 & 38 & 460 \\
\hline Price & 17 & 22 & 56 & 101 & 129 & 89 & 46 & 460 \\
\hline Trad. Media & 124 & 68 & 75 & 80 & 64 & 36 & 13 & 460 \\
\hline New Media & 106 & 50 & 61 & 74 & 88 & 64 & 17 & 460 \\
\hline WOM & 22 & 31 & 51 & 86 & 121 & 97 & 52 & 460 \\
\hline Experience & 15 & 4 & 3 & 19 & 47 & 165 & 207 & 460 \\
\hline
\end{tabular}

TABLE 4. PERCENTAGES FROM TABLE 3

\begin{tabular}{|c|c|c|c|c|c|c|c|c|}
\hline & 1 & 2 & 3 & 4 & 5 & 6 & 7 & \\
\hline Brand & $8.0 \%$ & $8.7 \%$ & $16.1 \%$ & $23.0 \%$ & $21.7 \%$ & $14.1 \%$ & $8.3 \%$ & $100 \%$ \\
\hline Price & $3,7 \%$ & $4,8 \%$ & $12,2 \%$ & $22,0 \%$ & $28,0 \%$ & $19,3 \%$ & $10,0 \%$ & $100 \%$ \\
\hline Trad. Media & $27,0 \%$ & $14,8 \%$ & $16,3 \%$ & $17,4 \%$ & $13,9 \%$ & $7,8 \%$ & $2,8 \%$ & $100 \%$ \\
\hline Sites/Blogs & $23,0 \%$ & $10,9 \%$ & $13,3 \%$ & $16,1 \%$ & $19,1 \%$ & $13,9 \%$ & $3,7 \%$ & $100 \%$ \\
\hline WOM & $4,8 \%$ & $6,7 \%$ & $11,1 \%$ & $18,7 \%$ & $26,3 \%$ & $21,1 \%$ & $11,3 \%$ & $100 \%$ \\
\hline Experience & $3,3 \%$ & $0,9 \%$ & $0,7 \%$ & $4,1 \%$ & $10,2 \%$ & $35,9 \%$ & $45,0 \%$ & $100 \%$ \\
\hline
\end{tabular}

\begin{tabular}{|c|c|c|c|c|c|c|c|}
\hline & 1 & 2 & 3 & 4 & 5 & 6 & 7 \\
\hline Brand & 37 & 77 & 151 & 257 & 357 & 422 & 460 \\
\hline Price & 17 & 39 & 95 & 196 & 325 & 414 & 460 \\
\hline Trad. Media & 124 & 192 & 267 & 347 & 411 & 447 & 460 \\
\hline Sites/Blogs & 106 & 156 & 217 & 291 & 379 & 443 & 460 \\
\hline WOM & 22 & 53 & 104 & 190 & 311 & 408 & 460 \\
\hline Experience & 15 & 19 & 22 & 41 & 88 & 253 & 460 \\
\hline
\end{tabular}

This initial data count already gives some interesting and important hints. Traditional media and new media have a similar trend, with a majority of "low impact" (vote: 1) on purchase decision. New media have a perceivable edge in the higher numbers (votes: 5 and 6). The following chart shows a comparison among the two. This shows how reviews and information appearing on sites, forums and blogs are more important to the respondents, than traditional media.

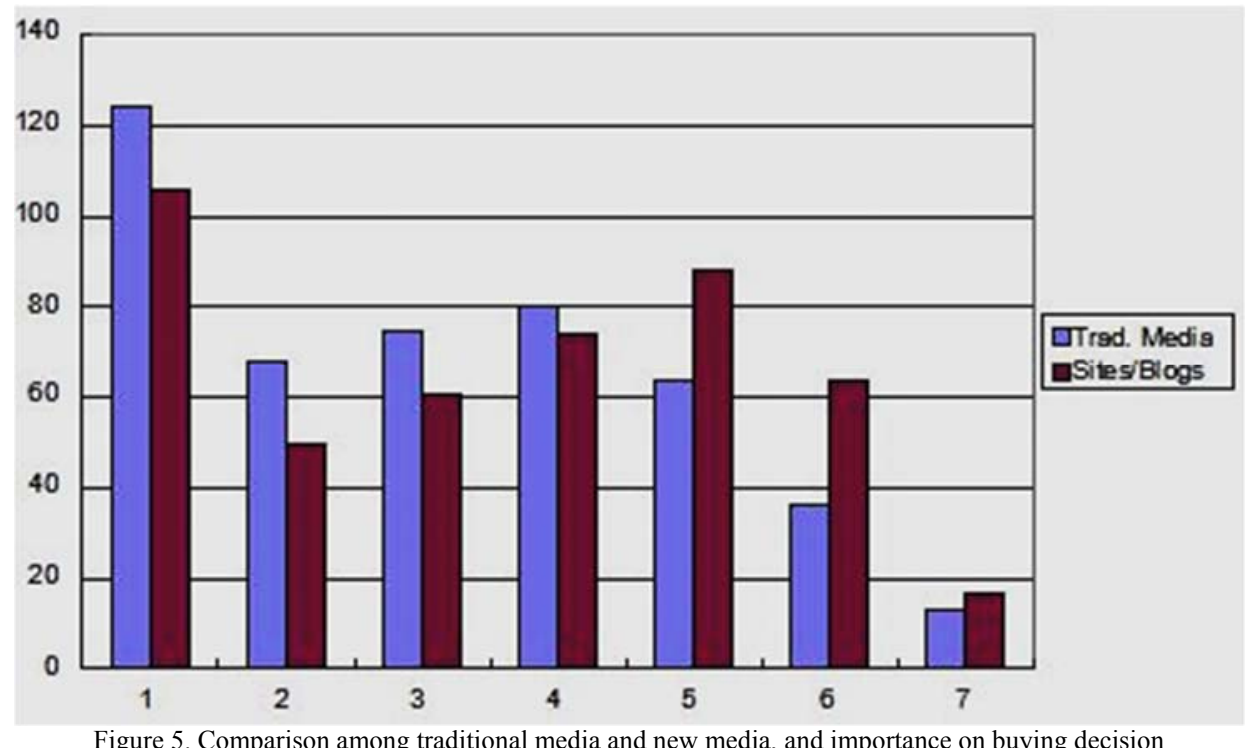

From the gathered data, it is evident how both price and WOM are considerable more important than both traditional and new media, and very similar in the trend of votes. This is depicted in the following chart. 


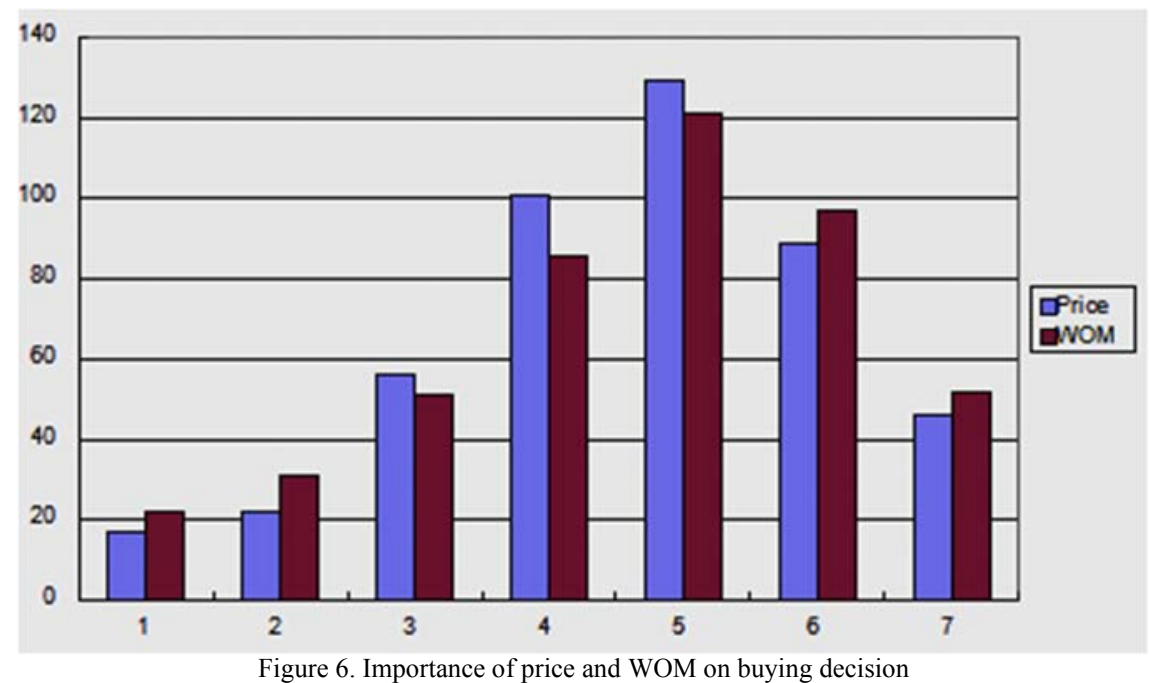

Brand seems not to be as important as price or WOM, but a bit more than advertisements or reviews. The factor which is most important is previous experience, even if, as already stated, one year's wine can considerably differ from the one tasted year(s) before. These two variables are depicted in the following chart.

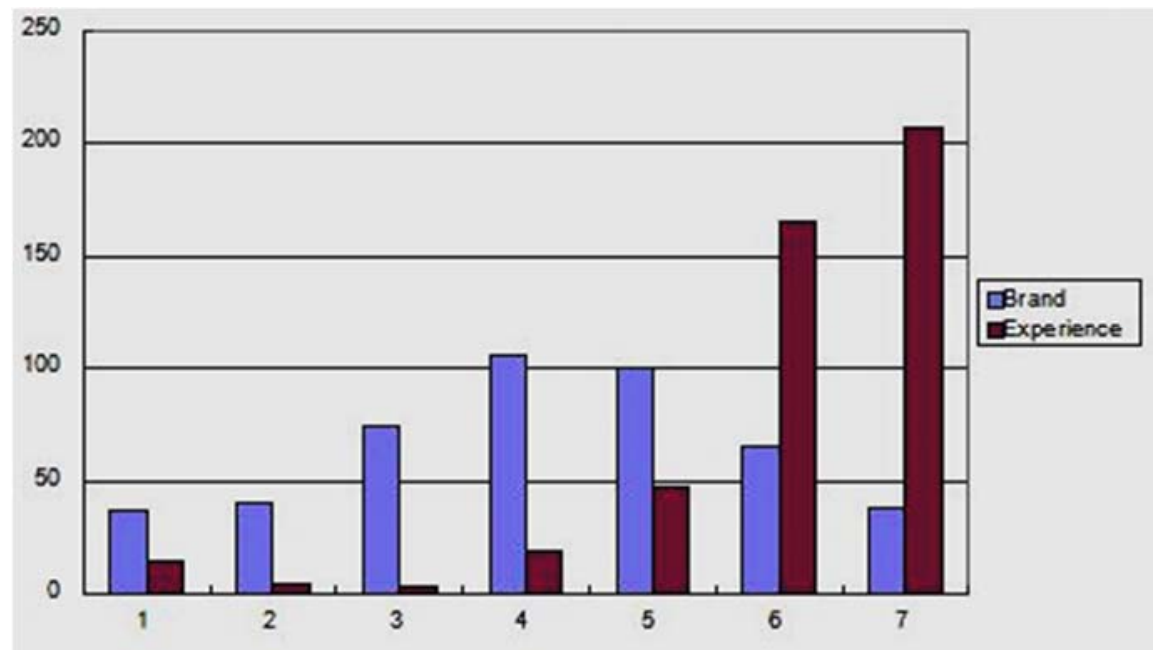

Figure 7. Importance of brand and previous personal experience on buying decision

\section{B. Basic Statistical Variables}

Also the statistical basic variables prove the mentioned trends. These values are calculated on the basis of the raw data. In a following session the same values will be explored for normalized data. In the following table, the average, standard deviation, mode and median is shown for each category.

\begin{tabular}{|c|c|c|c|c|c|c|}
\hline & Brand & Price & Trad. Media & New Media & WOM & Experience \\
\hline Average & 4,172 & 4,639 & 3,113 & 3,539 & 4,635 & 6,048 \\
\hline St. Dev. & 1,654 & 1,482 & 1,763 & 1,875 & 1,593 & 1,316 \\
\hline Median & 4 & 5 & 3 & $\overline{4}$ & 5 & 6 \\
\hline Mode & 4 & 5 & 1 & 1 & 5 & 7 \\
\hline
\end{tabular}

Once again traditional media and new media are similar, with an edge on the latter on the former. Both have an average vote among 3 and 4 (in a range of 1..7), a similar standard deviation, a median of 3 and 4 respectively and a mode of 1 . So the average value is slightly higher for the new media, and the median is 1 point higher, meaning that people give slightly more credit to what they read on websites, forums and blogs than to what they read on 
magazines or watch on TV. Price and WOM exhibit a very similar statistical behaviour, here, with an average of 4.6 , a standard deviation of about 1.5 , a median of 5 and a mode of 5. Brand seems to be slightly less important than WOM and price, but more significant of both new and traditional media.
The same analysis has been done by dividing the gathered data on the basis of the provenience of the respondents (i.e.: Websites/blogs, wineries, social channels).

The following table shows the data from the respondents coming from websites and blogs. It is important to divide the sources so to see how the data vary.

TABLE 7. STATISTICAL BASIC VARIABLES FOR QUESTIONNAIRES COMING FROM BLOGS/WEBSITES
\begin{tabular}{|l|r|r|r|r|r|r|}
\hline & Brand & Price & Trad. Media & New Media & WOM & Experience \\
\hline Average & 4,127 & 4,719 & 3,330 & 4,019 & 4,509 & 6,094 \\
\hline St. Dev. & 1,656 & 1,459 & 1,685 & 1,658 & 1,625 & 1,230 \\
\hline Median & 4 & 5 & 3 & 4 & 5 & 6 \\
\hline Mode & 4 & 5 & 1 & 5 & 5 & 7 \\
\hline
\end{tabular}

Not surprisingly, since these data come from the respondents on the web, the new media now have a more pronounced edge over traditional media and, according to the statistical variables shown here, seem to be about as important as brand, in wine purchase decision. WOM and price, again, are very similar, with a small edge for the price and again, personal experience leads the pack.

The next table represents the data from the respondents coming from wineries.

TABLE 8. STATISTICAL BASIC VARIABLES FOR QUESTIONNAIRES COMING FROM WINERIES
\begin{tabular}{|l|r|r|r|r|r|r|} 
& Brand & Price & Trad. Media & New Media & WOM & Experience \\
\hline Average & 4,338 & 4,324 & 2,606 & 2,577 & 5,000 & 6,099 \\
\hline St. Dev. & 1,594 & 1,510 & 1,832 & 1,925 & 1,434 & 1,148 \\
\hline Median & 5 & 5 & 2 & 2 & 5 & 6 \\
\hline Mode & 5 & 5 & 1 & 1 & 6 & 7 \\
\hline
\end{tabular}

It's immediately evident that, for the respondents coming from wineries, the influence of traditional media and new media on purchase decision is quite low, and similar, with a tiny edge for traditional media. Price and brand follow in importance and are almost identical in statistical relevance. WOM is much more important for this class of respondents than for the previous one, averaging a vote of 5 , a median of 5 and a mode of 6 .

The last table in this section shows the variables for the respondents coming from social networks and e-mails.

TABLE 9. STATISTICAL BASIC VARIABLES FOR QUESTIONNAIRES COMING FROM SOCIAL NETWORKS/E-MAILS

\begin{tabular}{l|r|r|r|r|r|r|} 
& Brand & Price & Trad. Media & New Media & WOM & Experience \\
\hline Average & 4,172 & 4,648 & 2,934 & 3,049 & 4,697 & 5,918 \\
\hline St. Dev. & 1,690 & 1,504 & 1,822 & 1,966 & 1,584 & 1,567 \\
\hline Median & 4 & 5 & 3 & 3 & 5 & 6 \\
\hline Mode & 4 & 5 & 1 & 1 & 5 & 7 \\
\hline
\end{tabular}

Here, again, traditional media are the least important influence in buying decision (average of slightly less than 3 , median of 3 and mode of 1 ), strictly followed by new media (average of slightly more than 3, median of 3 and mode of 1). WOM is again vastly important, with an average of about 4.7 , median and mode of 5 and price has very similar figures $(4.65,5$ and 5$)$. Brand has very similar statistical variables when compared to the questionnaires coming from blogs and websites, with an average of 4.2, median and mode of 4 . Personal experience is again the leading influencing factor.

Traditional media seems to be the less influencing channel, for wine purchase decision. The average of votes is less than 2 (in a 1..7 interval) and both median and mode are 1 . The standard deviation is also fairly low, showing that the votes are concentrated around the average. New media follow, with a slightly higher average vote (higher than 2) but also a higher standard deviation, meaning that votes are more spread around other values. Again, median and mode are equal to 1 . All the other channels seem to have much more impact on purchase decision. Brand and price both have an average higher than 4 (with a small edge for price), a median of 4 and 5 respectively and a mode of 6 and 5 respectively. WOM comes next, with an average of over 5 (again, in a $1 . .7$ interval), a median of 5 and a mode of 6. Not surprisingly, personal previous experience is again leading the group, with an average vote of more than 6 , with very low standard deviation, a median of 6 and a mode of 7 .

As a quick reference, the data have been summed up in the following tables, where the averages for each influencing variable are divided by the provenience of the respondent. 


TABLE 10. STATISTICAL AVERAGES, DIVIDED BY PROVENIENCE OF QUESTIONNAIRES
\begin{tabular}{|l|r|r|r|r|r|r|} 
& \multicolumn{1}{|c|}{ Brand } & \multicolumn{1}{|c|}{ Price } & Trad. Media & New Media & WOM & Experience \\
\hline Aggregate data & 4,172 & 4,639 & 3,113 & 3,539 & 4,635 & 6,048 \\
\hline Blogs/Sites & 4,127 & 4,719 & 3,330 & 4,019 & 4,509 & 6,094 \\
\hline Wineries & 4,338 & 4,324 & 2,606 & 2,577 & 5,000 & 6,099 \\
\hline Social channels & 4,172 & 4,648 & 2,934 & 3,049 & 4,697 & 5,918 \\
\hline
\end{tabular}

\section{Normalized Data}

The data have been normalized $(\mathrm{Nd})$, so that the summation of the votes for each respondent gives the same total. This has been done since the respondents could give any vote (symbolizing importance) to each variable, but it's also interesting to see how things would change if they had the same total to be divided among each variable. This has been achieved by calculating the average of the totals for each respondent $\left(M_{t}\right.$, resulting in 26.146) and then by dividing each real vote (D) by the real total of votes for the respondent (Td), and then by multiplying the result by the average of totals.

$$
N d=\left(\frac{D}{T d}\right) * M_{t}
$$

Formula 1. Normalization of data

In this way, of course, the individual votes are no longer ranging from 1 to 7 , and are no longer integer values.

In the following table, to be compared with table 6 , the same statistical variables are calculated for normalized aggregate data.

TABLE 11. STATISTICAL BASIC VARIABLES FOR NORMALIZED, AGGREGATE DATA

\begin{tabular}{l|r|r|r|r|r|r|}
\multicolumn{1}{c|}{ TABLE 11. STATISTICAL BASIC VARIABLES FOR NORMALIZED, AGGREGATE DATA } \\
\hline Average & 4,175 & 4,698 & 3,021 & 3,432 & 4,664 & 6,155 \\
\hline St. Dev. & 1,572 & 1,569 & 1,514 & 1,619 & 1,603 & 1,572 \\
\hline Median & 4,217 & 4,614 & 2,905 & 3,735 & 4,754 & 6,101 \\
\hline Mode & 4,358 & 5,229 & 4,358 & 4,358 & 5,229 & 6,536 \\
\hline
\end{tabular}

The difference is not big, and the order of importance of the factor influencing the purchase decision is the same as for the not normalized data (Experience, followed by price, WOM, brand, new media and traditional media).
In the next table, the average for normalized data is reported for each provenience of the questionnaires (to be compared with table 10).

TABLE 12. STATISTICAL AVERAGES FOR NORMALIZED DATA, DIVIDED BY PROVENIENCE OF QUESTIONNAIRES
\begin{tabular}{|l|r|r|r|r|r|r|}
\hline & Brand & Price & Trad. Media & New Media & WOM & Experience \\
\hline Aggregate data & 4,175 & 4,698 & 3,021 & 3,432 & 4,664 & 6,155 \\
\hline Blogs/Sites & 4,021 & 4,640 & 3,189 & 3,856 & 4,409 & 6,031 \\
\hline Wineries & 4,562 & 4,539 & 2,600 & 2,629 & 5,301 & 6,516 \\
\hline Social channels & 4,286 & 4,920 & 2,900 & 2,972 & 4,851 & 6,216 \\
\hline
\end{tabular}

So also with normalized data, the traditional media is the least influencing factor for wine purchase decision. New media follow, with a pronounced edge for respondents coming from blogs and websites and a subtle edge for those coming from wineries and social channels. Brand follows for the respondents coming from blogs/sites and social channels, while for the respondents coming from wineries this factor has a subtle advantage on price. Price and WOM have a similar influence in aggregate data, but price is more important for respondents coming from blogs and social channels, while for those coming from wineries WOM has the edge. Previous personal experience, as already discussed, is the most important factor for purchase decision.

\section{Averages for Each Class of Expense}

Data have been divided by classes of expense, as shown in table 1 . The average of each factor is studied by each of these classes, in table 13. 
TABLE 13. AVERAGES FOR EACH FACTOR, DIVIDED BY CLASS OF EXPENSE

\begin{tabular}{l|r|r|r|r|r|r|} 
& Brand & Price & Trad. Media & New Media & WOM & Experience \\
\hline $0-49 €$ & 4,091 & 4,922 & 2,890 & 3,201 & 4,870 & 5,896 \\
\hline $50-99 €$ & 4,395 & 4,822 & 3,158 & 3,691 & 4,638 & 6,118 \\
\hline $100-149 €$ & 3,954 & 4,385 & 3,431 & 3,708 & 4,415 & 6,138 \\
\hline $150-199 €$ & 4,613 & 4,000 & 3,484 & 4,000 & 4,742 & 6,032 \\
\hline $200-249 €$ & 4,217 & 4,739 & 3,478 & 3,957 & 4,130 & 6,261 \\
\hline $\mathbf{2 5 0} €$ & 3,543 & 3,571 & 2,743 & 3,371 & 4,229 & 6,114 \\
\hline
\end{tabular}

The first variable that should radically change among these classes is price. In fact, those spending less (0-49€) are more sensitive to this factor (average of over 4.9) and this remains valid for the following class of expense (50$99 €)$, where the average is 4.8 . The importance of price diminishes in the next class of expense (100-149€), with an average of less than 4.4 and further decreases for the next class (150-199€), where it reaches the average of 4 . Strangely enough, for the next class $(200-249 €)$ the price factor is again very important (average of 4.7). This could be due to the fact that people spending this much in wine perhaps do that for their own job (e.g. restaurant, bars) and thus are quite keen to the price, when purchasing wines. The highest class (expenditure equal or higher than $250 €$ ) show that price is not a very compelling factor, with an average of about 3.6. Perhaps those belonging to this class are mainly wine collectors, or people that simply want the best, without paying too much attention to price.

The other factor varying quite a lot, by changing class of expense, is brand. This factor matter most to those spending among 150 and $199 €$ (average 4.6), while it matter the least to those spending over $250 €$ (average of $3.5)$. For the others the average is among $4(100-149 €)$ and 4.4 (50-99€).

The influence of traditional media, once again, is the least important factor, no matter the class of expense. For those spending less $(0-49 €)$ and for the higher class $(>250 €)$ the average importance of this factor is respectively of 2.9 and 2.7. This factor is a bit more important for those in the other classes, being at about 3.2 for the class 50-99€ and around 3.4-3.5 for the other classes.

Slightly more important, but still in the back positions after traditional media, is the influence of new media. Here, again, the least influenced by this factor are those spending less money (average of 3.2 for the class $0-49 €$ ) and those spending the most (average of 3.4 for those spending $>250 €$ ). For those spending among 50 and $149 €$ ( 2 classes) the average is about 3.7 , while for those spending among 150 and $249 €$ (again, 2 classes) the average is 4 .

WOM has already proven to be an important influencing factor in the previous analysis and this division in classes of expense further confirms this. In fact, for all the classes the average is higher than 4 , with a maximum value of almost 4.9 for the lower class $(0-49 €)$ and a minimum value of 4.1 for the class $200-249 €$.

Previous personal experience is still leading, with average values higher than 6 for all the classes, but the lowest one (that has an average of 5.9).

\section{E. Summing up the Results}

Advertisement coming from traditional media and new media have a similar trend, with a majority of "low impact" (vote: 1) on purchase decision, but new media have a perceivable edge in the higher numbers (votes: 5 and 6). From the gathered data, it is evident how both price and WOM are considerable more important than communication and advertisement coming from both traditional and new media, and are very similar in the trend of votes. Brand seems not to be as important as price or WOM, but a bit more than advertisements or reviews. The factor which is most important is previous experience even if, as already stated, one year's wine can considerably differ from the one tasted in the past.

\section{INFORMATION DIFFUSION: EVALUATION BY MEANS OF A SIMULATION MODEL}

After having analysed the results coming from the questionnaire, an agent based simulation model is built, used to evaluate the potential difference in information diffusion, with regards of wine, in a scenario where social media are not used by the company in spreading messages about their products, compared to one where social media are used and potentially impact the buying decisions (as evident from the questionnaire).

The model used is quite straightforward; it's bottom-up, in the sense that the rules are defined for the individual entity and the collective behaviour emerges from the interaction of the entities. This is ideal to study complex situations where the emerging result is what really matters.

In the specific case, the individual agents (representing people) are connected over a network, with random links derived from a parameter called: "average number of links per agent". This is used defined, before the simulation starts. When an agent has an information, he can decide to pass it through her network, according to two parameters called "probability to diffuse" and "diffusion force". The 
first one influences how many connections the agent will pass the message to (e.g. a probability of $50 \%$ means that the agent will, on average, pass the message to half of her network neighbours). The second parameter deals with the strength of the diffusion (e.g. a value of $50 \%$ means that a contacted agent has $50 \%$ of probability of retaining the received information and pass it in turn, while a value of $100 \%$ means that a contacted agent will certainly receive and spread the message in turn). Another important parameter is the "individual duration (persistence) of the information" held by an individual agent. This is expressed in the number of "turns", or simulation steps, during which the agent is bearer of the message. This parameter can coincide with the period during which the agents tries to spread the information, or differ from it (in that case another parameter could be defined, namely "duration of diffusion"). In the former case, the agent will go on spreading the message for all the steps during which he cares about the information, while in the latter case the agents will stop spreading the message after $\mathrm{n}$ steps, even if she still "cares" about it.

Besides, an agent could be endowed by a sort of "immunity" to a message, especially after that he stopped caring about it (i.e. when the period called "persistence of the information" is over). If this parameter is activated, the agent won't receive the same information again, if she already had it and stopped caring. This "immunity" can be indefinite, meaning that the agent won't receive the same message anymore, or can be defined by a parameter, called "duration of immunity", again determined by a parameter called "duration of immunity".

In the used model, all the entities are interacting agents. The set of agents is composed by three main categories. This has been introduced to allow different linking possibilities among the agents; in particular, the first category can only be linked to the second, and at the same way also the third can only be linked to the second. The second, on the contrary, can be linked with the first, the third and also with itself. For a basic diffusion model, in which no rules for the linking connectors are considered, the second category of agents can be employed alone (without using the first or the third), so that they all are at the same hierarchical level and can be connected among them with no restrictions. The total number of possible links, if only the second category of agents is present, equals to:

$$
\operatorname{Maximum} \operatorname{links}(n)=n *\left(\frac{n-1}{2}\right)
$$

Formula 2. Maximum theoretical number of links in the model, given the number of agents

If also other categories were used, the previous formula changes to:

$$
\text { Maximum links }(m, n, o)=n *\left(m+p+\frac{n-1}{2}\right)
$$

Formula 3. Maximum theoretical number of links in the model, given the number of agents for each category

Where $\mathrm{m}$ is the number of agents of the first category, $\mathrm{n}$ the number of those belonging to the second and o the number of the agents of the third category.

The first step in the model is the random network creation, given the number of agents and their kinds. In the scenario presented in the present paper, only agents belonging to the second category were used. So the formula used to have the actual number of links for a given scenario is:

$$
\text { Actual links }(n, P)=P * n *\left(\frac{n-1}{2}\right)
$$

Formula 4. Actual number of links in the model, given the number of agents and the connection probability

Where $\mathrm{n}$ again is the number of agents and $\mathrm{P}$ is the connection probability (both are user settable parameters).

At every step of the simulation, the list of agents reached by a message is considered. For each agent, the list of "neighbours" (i.e. the list of connected agents) is considered. For each of those, if not already reached by the message, the probability of being reached by the message is computed according to the user defined parameter. So, if the "diffusion strength" is $10 \%$ and the "probability of contact" is $20 \%$, the resulting probability to diffuse a message is $2 \%$, meaning that an agent will succeed in passing over a message to 2 of her neighbours, out of 100 .

If an agent is "immune" to the message, it won't be reached by the message even if the previous rule applies. If an agent is reached by a message and the "interest time" is defined, she will go on spreading the message for that period, and then she'll become immune (again, for a defined period).

In figure 8 a flow chart is shown of the process involving each of the agents reached by the message. 


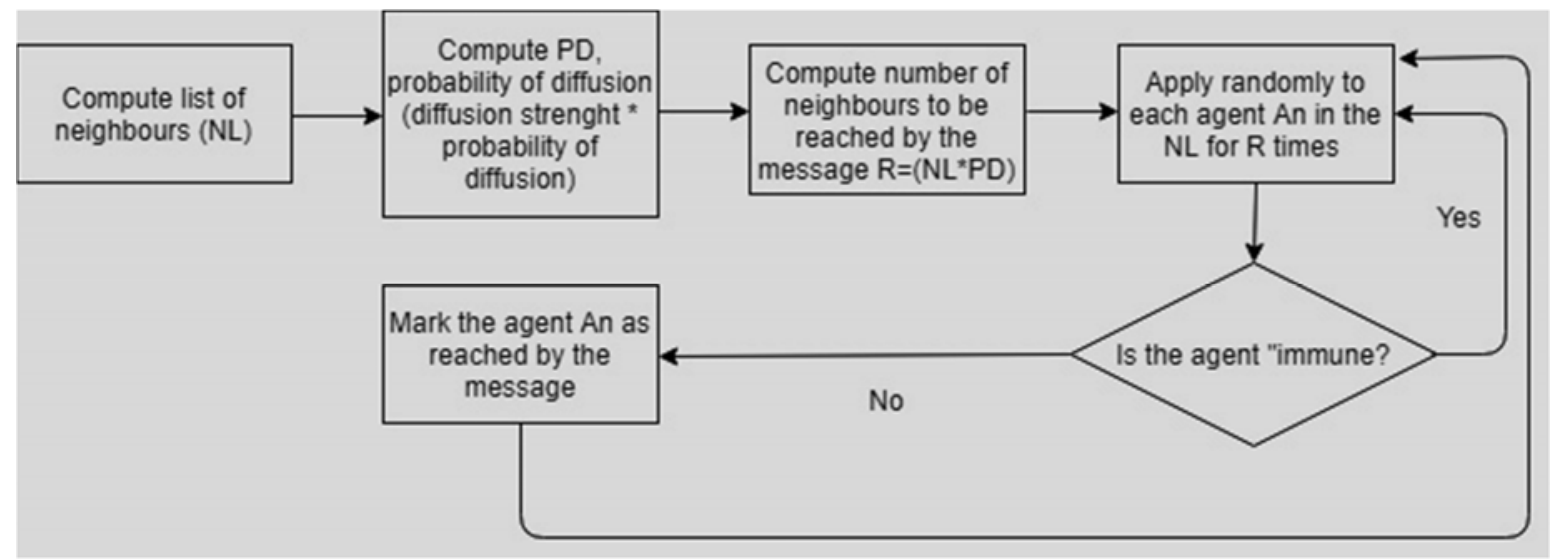

Figure 8 . The process of message diffusion for each of the agents

The simulator computes and draws on a graph, for each turn, the percentage of agent reached by the message and the number of immune agents.

In order to represent the two situations that we mean to simulate (the diffusion of a message) with or without the use of social media, two scenarios have been built, differing by the probability of contact, $20 \%$ higher in the case in which the wine company made use of social media. The percentage was computed by taking into account the difference coming out from the questionnaire (3.432 vs 3.021 ) and increasing it of a further $5 \%$ due to the fact that also WOM is stronger when social channels are used (eWOM). For the specific case, relative to the impact of "new media" in wine buying decision, we got from the questionnaire that this factor has a quite important role in buying wine, especially when the respondents came from internet channels, hence it becomes crucial to check how many people are indeed reached by a specific message to compare the two situations and verify how much useful could potentially be for a wine company to use social media in its communication campaign and overall strategic marketing and management.

In the following graph (figure 9) the situation where no social media/blogs are used by the company is depicted. We can summarize this case as the one where the company uses only traditional media to capture the interest of people and advertising its own products. The result is straightforward, where the company succeed in diffusing the message to about $50 \%$ of potential buyers within the initial period, and then the percentage of customers potentially interested in the product fluctuates among $25 \%$ and $40 \%$, slowly getting to about $35 \%$ average in the medium run. We can connect this with the typical trend for marketing, where a company has to reissue new campaigns every few months, in order to revive the customers' interest in its products.

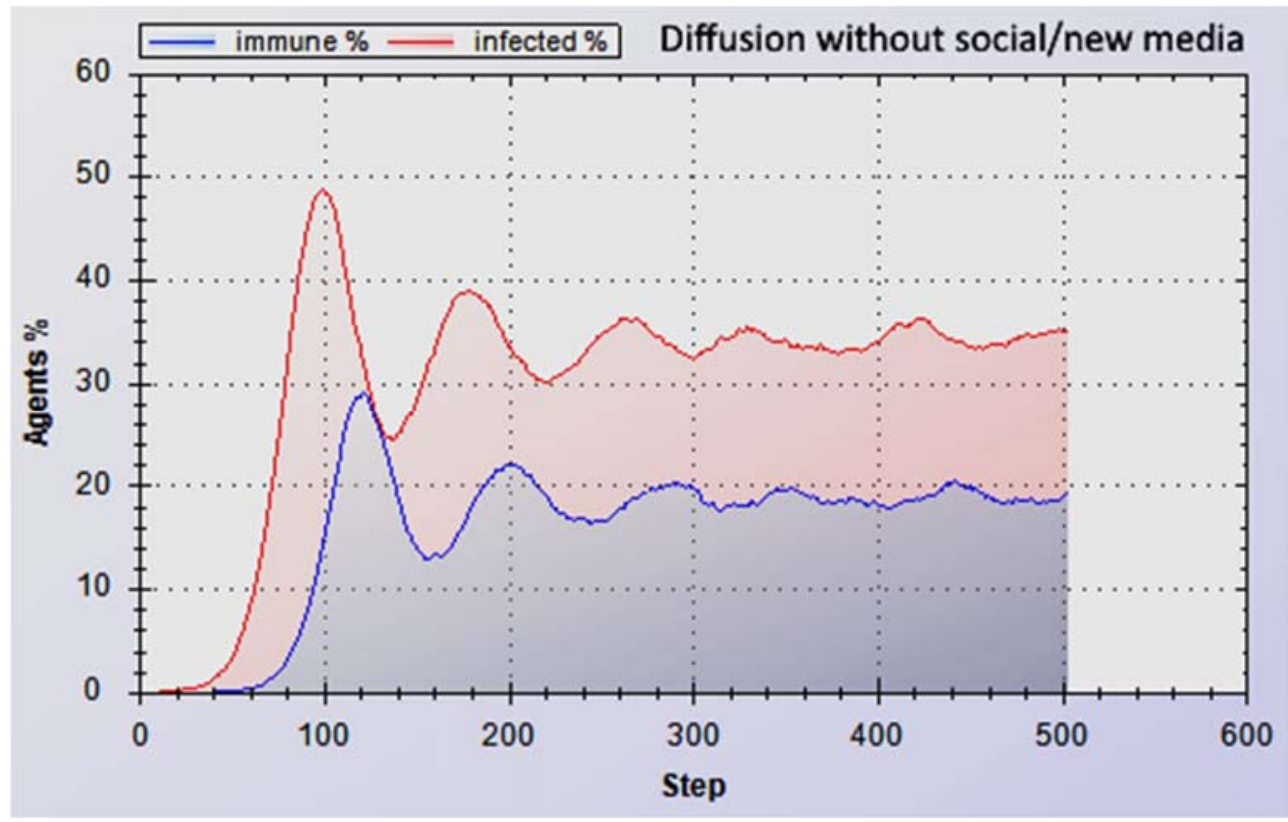

Figure 9. Company communication about the product coming only from traditional media 
In the second graph coming from the simulator (figure 10), the company uses social/new media as an additional marketing mean for its wines. As already detailed, this impacts the perception of potential customers in general, but more and more that of those using the social channels.

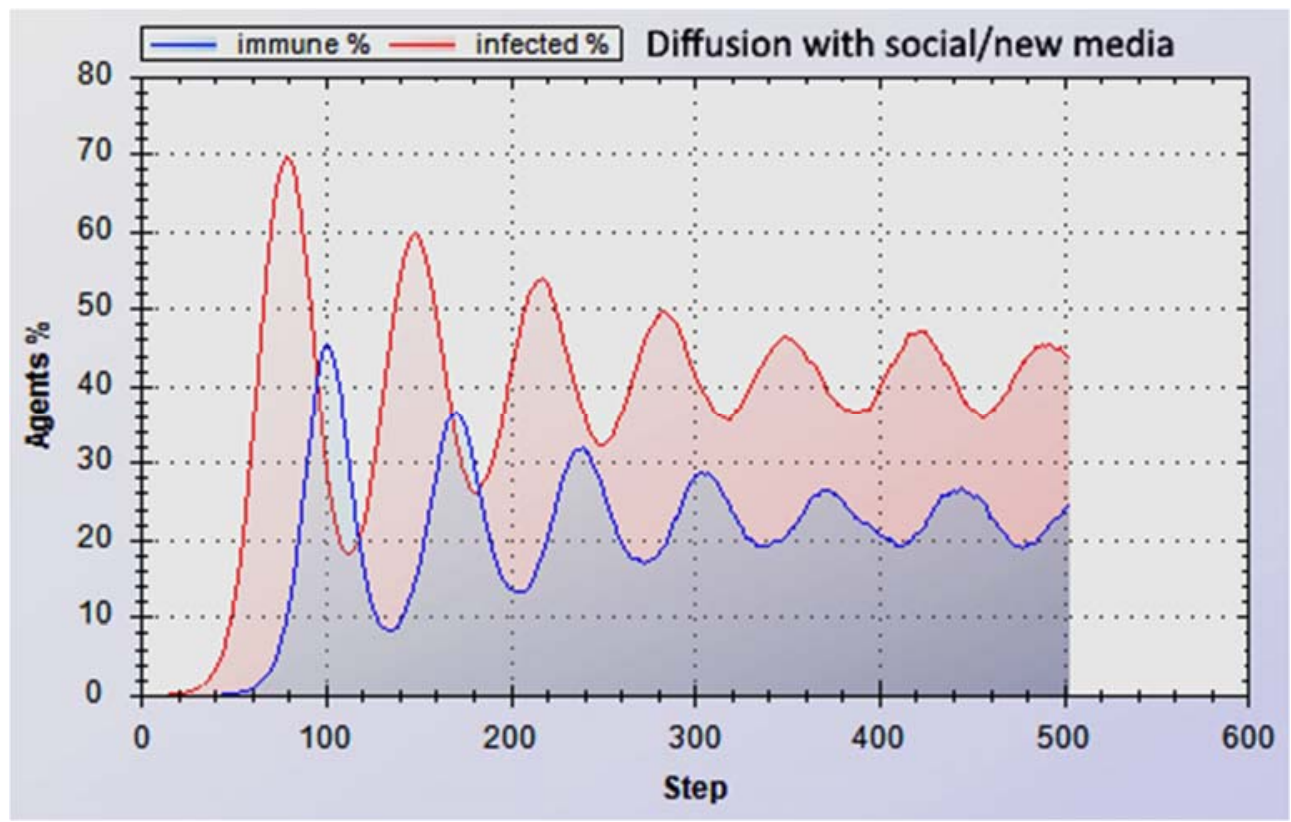

Figure 10. Company communication about the product coming also from social/new media

Again, the impact of the marketing campaign is particularly strong within the immediate simulation steps (the maximum diffusion is now reached sooner, after about 75 steps). Something to notice here is that when new media are involved, the percentage of agents reached is higher than before, on average, but less stable (ranging from about $20 \%$ to $60 \%$, after an initial peak of about $70 \%$ ). This is typical of internet marketing, where the message is more pervasive, but also perceived as less stable by potential customers. Anyway, as time goes by, the average percentage of agents reached is about $42 \%$ after 500 simulated steps, which is higher than the one seen in figure 1.

\section{CONCLUSIONS}

The present research has a twofold purpose. On one side, it aims to empirically evaluate the impact of both new and traditional communication media on wine buying decisions and compare these factors with others, like brand, price and previous personal experience. This is done by means of an extensive questionnaire, diffused through wineries, social channels and specialized blogs/websites. A total of 460 questionnaires were collected and analysed. In the questionnaire addressed to potential customers, advertisement coming from traditional media and new media have a similar trend, with a majority of "low impact" (vote: 1) on purchase decision, but new media have a perceivable edge in the higher numbers (votes: 5 and 6).
From the gathered data, it is evident how both price and WOM are considerable more important than communication and advertisement coming from both traditional and new media, and are very similar in the trend of votes. Brand seems not to be as important as price or WOM, but a bit more than advertisements or reviews. The factor which is most important is previous experience even if, as already stated, one year's wine can considerably differ from the one tasted in the past.

On the other side, a simulation model has been employed to quantitatively show the potential difference among a marketing campaign in the wine business carried on only with traditional media, and one with the use of also new/social media. Two scenarios have been simulated through a bottom-up agent based model and the results show a perceivable edge for the strategy employing social media (a peak of about $70 \%$ of potentially interested buyers is reached after few simulation steps, versus a peak of less than $50 \%$ in the case where only traditional media are employed). This simulated evidence, along with the results coming from the questionnaire show, without a doubt, that even for a traditional good like wine, new and social media have a very important role in information diffusion and driving force in buying decision.

\section{REFERENCES}

[1] Batt, P.J., \& Dean, A., (2000), "Factors influencing the consumer's decision, Australia and New Zealand Wine Industry", Journal Marketing Supplement, Vol. 15. 
[2] Capitello et al. (2013), "Social media strategies and corporate brand visibility in the wine industry", Euromed Journal of Business, n.9, pp. 129-148.

[3] De Winter J. C. F. et al. (2010), "Five-point Likert items: t test versus Mann-Whitney-Wilcoxon”, Practical Assessment, Research \& Evaluation, Vol. 15, No. 11.

[4] Hall, J., and Winchester, M., (2002), "An empirical confirmation of segments in the Australian wine market", International Journal of Wine Marketing, vol. 3.

[5] Howard, R., and Stonier, J., (2002), "Marketing wine to Generation X", The Australian and New Zealand Wine Industry Journal, May/June.

[6] Jenster, P. and Jenster, L., (1993), "The European wine industry", International Journal of Wine Marketing, vol. 5.

[7] Karjaluoto H., et al., (2005), "Factors Affecting Consumer Choice of Mobile Phones: Two Studies from Finland," Journal of Euromarketing, Vol.14, No. 3.

[8] Koewn, C., and Casey, M., (1995), "Purchasing Behaviour in the Northern Ireland Wine Market”, British Food Journal, vol. 97.

[9] Mattiacci A., Ceccotti F., De Martino V. (2006), "Il vino come prodotto cognitivo: indagine esplorativa sui comportamenti giovanili", Convegno internazionale "Le tendenze del Marketing".

[10] Mills et al. (2011), "Reading between the vines: analyzing the readability of consumer brand wine web sites", International Journal of Wine Business Research, n.24, pp. 169-182.

[11] Osenton, T., (2002), "Customer Share Marketing", Prentice Hall.

[12] Seneca S, Nantel, (2004), "The influence of online product recommendations on consumers' online choices", Journal of Retailing, vol. 80 , no. 2.

[13] Szolnoki et al. (2014), "Using social media in the wine business, an exploratory study from Germany", International Journal of Wine Business Research, n.26, pp. 80-96.

[14] Wind, Y., Mahajan, V., \& Gunther, R.E., (2002), "Convergence Marketing: Strategies for Reaching the New Hybrid Consumer", Prentice Hall. 